Canadian

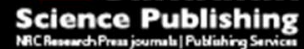

Canadian Journal of Chemistry Revue canadienne de chimie

\title{
NANOSILICA A-300 INFLUENCE ON WATER STRUCTURES FORMED ON THE BIOACTIVE AGENT ENOXIL
}

\begin{tabular}{|r|l|}
\hline Journal: & Canadian Journal of Chemistry \\
\hline Manuscript ID & cjc-2015-0360.R1 \\
\hline Manuscript Type: & Article \\
\hline Date Submitted by the Author: & $19-$ Sep-2015 \\
\hline Keymote List of Authors: & $\begin{array}{l}\text { Turov, Vladimir ; O. O. Chuiko Institute of Surface Chemistry } \\
\text { Lupascu, Tudor; Institute of Chemistry of the Academy of Sciences of } \\
\text { Moldova } \\
\text { Krupska, Tatyana; O. O. Chuiko Institute of Surface Chemistry } \\
\text { Povar, Igor; Institute of Chemistry, Academy of Sciences of Moldova, }\end{array}$ \\
\hline & $\begin{array}{l}\text { antacid properties, bioactive Enoxil preparation, composite Enoxil/SiO2, } \\
\text { low-temperature NMR spectroscopy, thermodynamic propert }\end{array}$ \\
\hline &
\end{tabular}

SCHOLARONE $^{\text {tw }}$

Manuscripts 


\title{
NANOSILICA A-300 INFLUENCE ON WATER STRUCTURES FORMED ON THE BIOACTIVE AGENT ENOXIL
}

\author{
Vladimir V. Turov ${ }^{1}$, Tudor Lupascu ${ }^{2}$, Tatyana V. Krupska ${ }^{1}$ and Igor Povar ${ }^{2}$

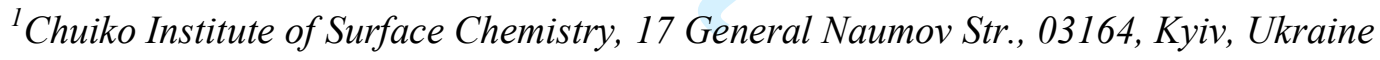 \\ ${ }^{2}$ Institute of Chemistry of the Academy of Sciences of Moldova, 3 Academiei Str., \\ 2028, Chisinau, Republic of Moldova
}

Corresponding author: Igor Povar (e-mail: ipovar@yahoo.ca) 
Abstract: The interactions of water and aqueous solutions of $\mathrm{HCl}$ with the Enoxil preparation and its composite system (1:1) Enoxil/SiO $\mathrm{S}_{2}$ have been studied by low-temperature ${ }^{1} \mathrm{H}$ NMR spectroscopy. The antacid properties in the preparation, manifested in the transformation of concentrated solution of $\mathrm{HCl}$ in a weakly concentrated one, have been established. In the composite system adsorbed hydrochloric acid in a hydrophobic environment of $\mathrm{CDCl}_{3}$ may generate a system of clusters with different acid concentration, while the equilibrium is shifted toward less concentrated forms.

Key words: antacid properties, bioactive Enoxil preparation, composite Enoxil/ $/ \mathrm{SiO}_{2}$, lowtemperature NMR spectroscopy, thermodynamic properties of bound water.

Résumé:Par la spectroscopie RMN à basse température,les interactions de l'eau et des solutions aqueuses de $\mathrm{HCl}$ avec la préparation Enoxil et son système composite $(1: 1)$ Enoxil/SiO $\mathrm{S}_{2}$ ont été étudiés. Les propriétés anti-acides de la préparation, qui se manifestentpar la transformation de la solution concentrée de $\mathrm{HCl}$ dans une faiblement concentrée, ont été établis. Dans le système composite, l'acide chlorhydrique adsorbé dans un milieu hydrophobe de $\mathrm{CDCI}_{3}$ peut générer un système de clusters avec une concentration d'acide différent, tandis que l'équilibre est déplacé vers des formes moins concentrés.

Mots clés: propriétés antiacides, préparation bioactive Enoxil, composite Enoxil/ $\mathrm{SiO}_{2}$, spectroscopie RMN à basse température, propriétés thermodynamiques de l'eau liée. 


\section{Introduction}

The Enoxil preparation, developed by the Institute of Chemistry of the Academy of Sciences of Moldova [1], is a set of biologically active substances, obtained by extraction from grape seeds $[2,3]$. The final product is a powder of yellow-brown color, soluble in water, which has high antioxidant properties as proved by voltammetric studies [4]. On the basis of biologically active complex Enoxil, new pharmaceuticals have been developedwith curative properties for the treatment of bacterial and fungal infections in the process of regeneration of thermal, physical and chemical burns, ulcers and for the treatment of postoperative wounds and post-radiation damage of cancer patients, as well as traumatic injuries of soft tissue and inflammation lesions of the children maxillofacial region [5-7].

Further enhancementof the preparations of Enoxil group may be performed by immobilization on the surface of non-porous nanosilica [8], allowed for use as food additives and fillers [9]. A comparative study of the antimicrobial action of chloramphenicol in free and immobilized states on the nanosilica A-300 surface shows that the effectiveness of the immobilized preparationis higher by almost $20 \%$ [10]. It has been suggested that the cause of this effect is the formation at the interfaces of silica nanoparticles with hydrophobic regions of the cell surface layers of water, enriched by little associated water (forming only few hydrogen bonds with its neighbors) [11]. Thereby, the penetration of adsorbed biologically active compounds on the silica surface into cellsis facilitated, increasing the bioavailability of preparations. A similar effect of the nanosilica action can be expected in the case of creation of nanocomposite systems with the water soluble Enoxil.

The aim of this work has been to study the hydration process of Enoxil and the structure of associated water layers in native and immobilized states on the surface of 
nanosilica A-300, as well the effects of the presence of hydrochloric acid, which is part of the gastric juice.

The most promising method of recording the parameters of the water layers in complex heterogeneous systems (including biological ones) is to compare the parameters of phase transitions, in particular, process of melting water or aqueous solutions. As a fundamental research method, the low-temperature ${ }^{1} \mathrm{H}$ NMR spectroscopy was chosen [1215], bymeans of which according tothe change in intensity of the NMR signal during the process of sample melting, the amount of strongly and weakly bound water can be determined, while using Gibbs-Thomson equation [16, 17], the distribution of the cluster radius of unfrozen water can be found. The magnitude of the chemical shift of water allows calculating the average degree of association of water molecules in poly-associates. This takes into account the fact that protons of unassociated (of weakly associated) water have chemical shift $\delta_{\mathrm{H}}=1-1.5 \mathrm{ppm}$, while ice-like structures have a chemical shift characteristic to hexagonal ice, $\delta_{\mathrm{H}}=7 \mathrm{ppm}[18]$.

\section{Experimental}

Hydro-packed nanosilica, was prepared by programmable humidification (followed by drying) of nanosilicaA-300 in Kalush Pilot Plant, Ukraine. As a result, nanosilica with a bulk density of about $200 \mathrm{~kg} / \mathrm{m}^{3}$ with a specific surface area of $285 \mathrm{~m}^{2} / \mathrm{g}$ were formed. The composite system of silica with Enoxil was created by thorough abrasion of dry Enoxil with nanosilica in an agate pounder for $20 \mathrm{~min}$.

NMR spectra were recorded on the NMR spectrometer of high resolution (Varian "Mercury") with an operating frequency of $400 \mathrm{MHz}$. Eight $60^{\circ}$ sounding pulses of duration $1 \mu \mathrm{s}$ at a bandwidth of $20 \mathrm{kHz}$ were used. The temperature in the sensor was regulated by the Bruker VT-1000 Temperature Controller with an accuracy of \pm 1 degree. The signal intensity 
was determined by measuring the peak areas using the procedure of signal decomposition into its components, assuming a Gaussian waveform and optimizing the zero line and phase with an accuracy that for well-resolved signals does not fall below $5 \%$ and for overlapping signals of $\pm 10 \%$. In order to prevent water super-cooling in the studied objects, measuring the concentration of non-freezing water was carried out by heating the samples, pre-cooled to a temperature of $210 \mathrm{~K}$. The temperature dependences of the intensity of NMR signals were carried out in an automated cycle, when the holding time of samplesat a constant temperature was 9 minutes, and the measurement time was 1 minute.

As the main parameter that determines the structure of the hydrogen bond network of water, the chemical shift of the protons $\left(\delta_{\mathrm{H}}\right)$ has been used. It has been assumed that the water in which each molecule involved in forming four hydrogen bonds (two due to protons and two due to the lone electron pairs of oxygen atoms) has a chemical shift $\delta_{\mathrm{H}}=7 \mathrm{ppm}$ (realized for hexagonal ice), and weakly associated water (not involved in the formation of hydrogen bonds as proton-donor) - the chemical shift $\delta_{\mathrm{H}}=1-1.5 \mathrm{ppm}$ [12-15]. For determining the geometric dimensions of clusters of the adsorbed water, the Gibbs-Thomson equation, relating the radius of the spherical or cylindrical water cluster or domain $(R)$ with the value of the freezing point depression [16,17], has been used:

$$
\Delta T_{m}=T_{m}(R)-T_{m, \infty}=\frac{2 \sigma_{s l} T_{m, \infty}}{\Delta H_{f} \rho R},
$$

wherein $T_{\mathrm{m}}(R)$ is the ice melting temperature, localized in the pores of radius $R, T_{\mathrm{m}, \infty}$ is the bulk ice melting temperature, $\rho$ denotes the solid phase density, $\sigma_{\mathrm{sl}}$ constitutes the solid-liquid interface energy and $\Delta H_{\mathrm{f}}$ is the bulk enthalpy of melting. For practical use, eq. (1) can be used in the form $\Delta T_{\mathrm{m}}=(k / R)$, where the constant $k$ for many heterogeneous systems, which contain water, is close to 50 degrees.nm [19]. The methodology of NMR measurements and methods of determining the radius of clusters of interfacial water have been described in detail in [12- 
15]. The clusters are considered poly-associates with a radius $R<2 \mathrm{~nm}$, while the larger polyassociates are nanodroplets or domains, as they contain several thousand molecules of water $[12]$.

The changes in the Gibbs free energy due to the effects of the limited space and the nature of the interface correspond to the process of freezing (melting) of bound water. The farther away the layer of water is from surface, the smaller differences are from the process in volume. At $T=273 \mathrm{~K}$ water freezes, the properties of which correspond to the bulk water, and with decreasing temperature (excluding the effect of hypothermia) the water layers, located closer to surface,freeze. For the free energy change of bound water (ice) the following relation is valid:

$$
\Delta G_{\text {ice }}=-0,036(273.15-T),
$$

where the numerical coefficient is a parameter, associated with the temperature coefficient of change of Gibbs free energy for ice [18]. Determining by the magnitude of signal intensity the temperature dependence of the concentration of unfrozen water $C_{u w}(T)$, in accordance with the procedure described in detail in [12-15], the quantities of strongly and weakly bound water and thermodynamic properties of these layers can be calculated.

Water interfacial energy at the interface with solid particles, or in aqueous solution was determined as the modulus of total lowering free energy of the water due to the presence of the phase boundary by the formula:

$$
\gamma_{S}=-K \int_{0}^{C_{\mathrm{max}}^{\max }} \Delta G\left(C_{\mathrm{uw}}\right) d C_{\mathrm{uw}},
$$

where $C_{\mathrm{uw}}^{\max }$ is the total quantity of unfrozen water at $T=273 \mathrm{~K}$.

Microphotography of the Enoxil powder was recorded using the microscope Primo Star (Carl Zeiss, Germany) at magnification ofx100, x400 and x1000 with immersion.

\section{Results and discussion}


The microphotography images of the Enoxil powder are shown in Fig.1.

The initial preparation is a collection of crystal structures (Fig. 1a) of irregular shape, with a broad particle size distribution (Fig. 1b,c). By mechanical activation of Enoxil with silica, the color of composite becomes yellowish due to the uniform distribution of Enoxil on the silica surface. Meanwhile, some particles of Enoxil, easily distinguishable on the background of silica, are retained in the composite (Fig. 1d). It is possible to establish the fact that the preparation is almost uniformly distributed over the surface of silica and crystal structures (Fig. 1e). In the field of view there are observed nanosilica aggregates of various sizes and a certain amount of small crystals of the preparation. In the presence of a small amount of water, the Enoxil crystals are dissolved and the formation of small conglomerates of silica up to 20 microns, as well as many aggregates of the size of about 1 micron, can be observed (Fig. 1f).

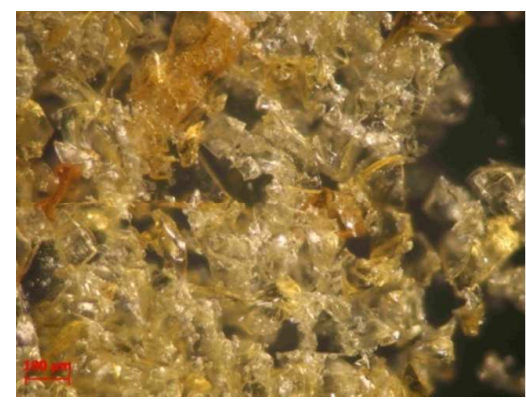

(a)

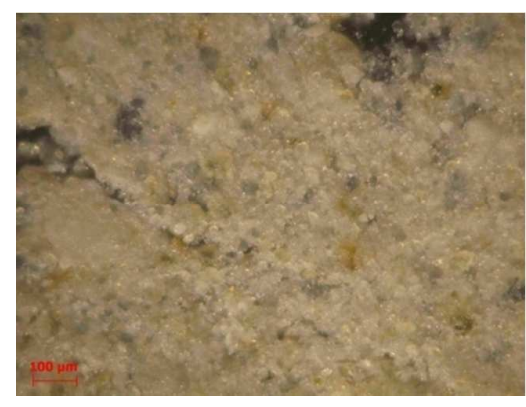

(d)

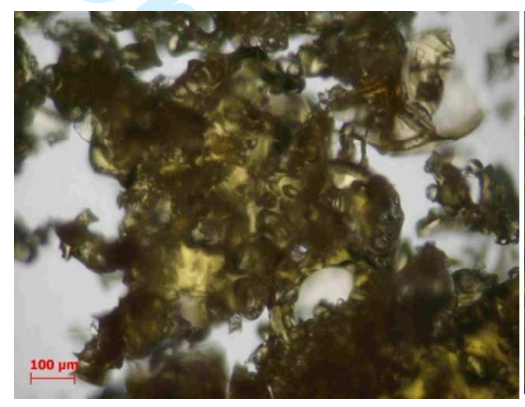

(b)

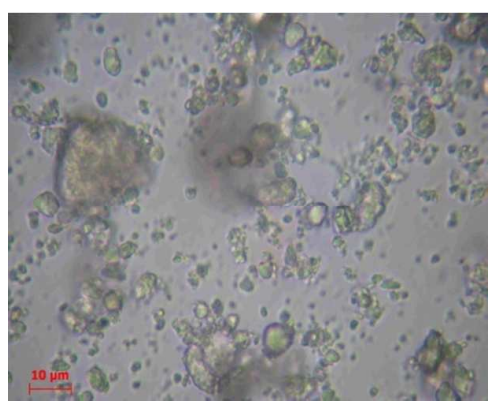

(e)

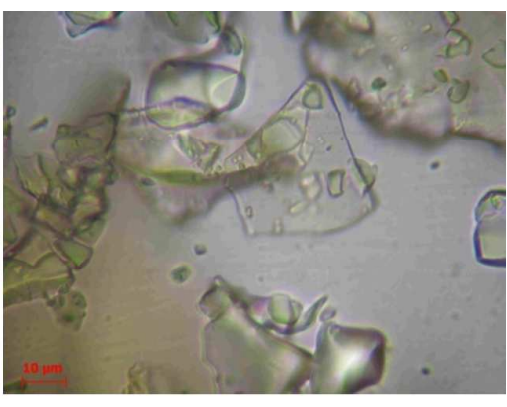

(c)

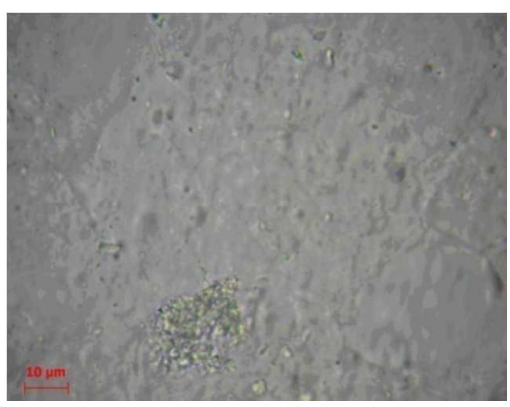

(f) 
Fig. 1.Microphotograph images of the initial Enoxil in its native state: $a$ - in the reflected light at $\mathrm{x} 100$ magnification; $b, c-$ in the transmission mode at $\mathrm{x} 100$ and $\mathrm{x} 1000$ magnification respectively; and also of the preparation fixed on the silica surface: $d$ - in reflection mode with increasing by $\mathrm{x} 100 ; e$ - in transmission mode with increasing by $\mathrm{x} 1000 ; f$ - in transmission mode at x1000 magnification in the presence of water.

The spectra ${ }^{1} \mathrm{H}$ NMR recorded at different temperatures of the initial powder of Enoxil are shown in Fig. 2a. In the spectra there are recorded one or more broadened signals within the spectral region $\delta_{\mathrm{H}}=0-3 \mathrm{ppm}$. With increasing temperature, the intensity of signal (s) significantly increases, while the basic growth rate is observed when the sample is heated from 271 to $290 \mathrm{~K}$. The sample weight moisture measurement method (heating to $380 \mathrm{~K}$ for 2 hours) shows that the residual moisture of the powder of Enoxil is $6 \mathrm{wt} \%$. Therefore, the observed increase in signal intensity at full melting of the sample can be attributed to the residual water. Considering that the chemical shift of water is less than $2 \mathrm{ppm}$, it can be concluded that water in Enoxil is in weakly associated state [12]. Besides the water signal, the observed signals may be correspond to methyl and methylene groups of grape oil.

When placing the powder of Enoxil into a liquid hydrophobic environment (deuterated chloroform), the width of signals is significantly reduced due to the increase of homogeneity of the sample [19] (Fig. 2b). In the spectra there are fixed two groups of signals: on the left different forms of weakly associated water (WAW), and on the right - methyl and methylene groups, mostly of grape oil. It should be noted that the composition of the solid Enoxil fraction includes sugar acids, phenolic compounds and other organic substances [2]. In the solid state they are not registered in the spectra due to the small transverse relaxation time of protons in these graphs [19]. 
Because the Enoxil can be used orally, the study of the influence of $\mathrm{HCl}$ solution on the state of hydrate cover is of considerable interest. Fig. 2c shows the plotted spectra of Enoxil powder in $\mathrm{CDCl}_{3}$ medium supplemented with $50 \mathrm{mg} / \mathrm{g}$ of $36 \%$ hydrochloric acid at differenttemperatures. Besides the signalsof WAW and grape oil, in the spectra an intensive signal of $\delta_{\mathrm{H}} \approx 8 \mathrm{ppm}$ appears within the spectral region(Fig. 3), the intensity of which decreases rapidly with decreasing temperature. In accordance with the data given in [20], the liquid hydrochloric acid is observed in the spectra as a single signal, which chemical shift decreases with increasing temperature from $\delta_{\mathrm{H}}=9.4 \mathrm{ppm}$ at $T=200 \mathrm{~K}$ to $\delta_{\mathrm{H}}=8.9 \mathrm{ppm}$ at $T=$ $290 \mathrm{~K}$, and its intensity at the given temperature range does not vary more than $30 \%$. Since the chemical shift of the aqueous solution of strong acids is directly proportional to the acidconcentration [19], as it can be seen in Fig. $2 c$, the signal can be attributed to water containing just a small amount of $\mathrm{HCl}$. Probably, the main part of hydrochloride is absorbed by solid components of the formulation and is not observed in the spectra of high resolution, i.e. the Enoxil preparation has a strong antacid effect.

The concentrated solution of Enoxil, containing $500 \mathrm{mg} / \mathrm{g}$ water, in the spectra is observed as a relatively narrow signal for which,with decreasing temperature, the intensity decreases sharply, and the chemical shift increases from $\delta_{\mathrm{H}}=5 \mathrm{ppm}$ at $T=290 \mathrm{~K}$ to $\delta_{\mathrm{H}}=$ $7.5 \mathrm{ppm}$ at $T=234 \mathrm{~K}$ (Fig. $2 d$ and Fig. 3). At the high sensitivity of the spectrometer on the right wing of water signal there appear complex signals, which can be caused by sugars and other organic compounds. 


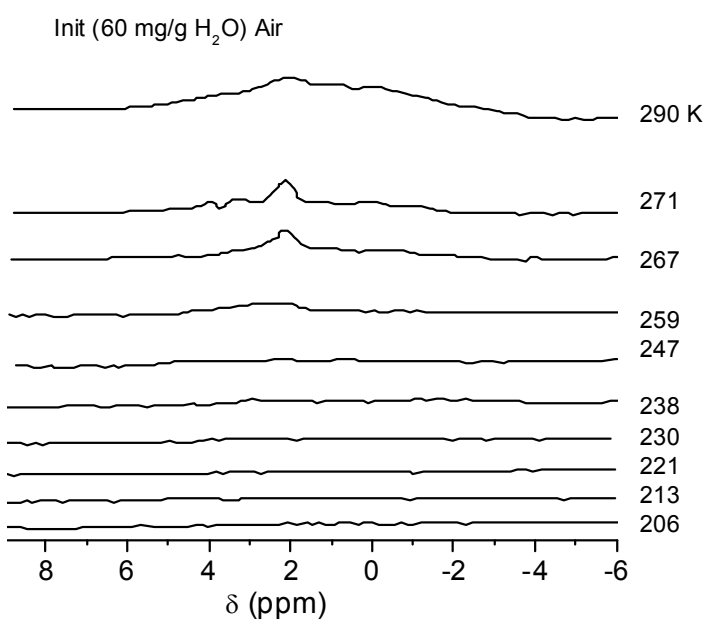

(a)

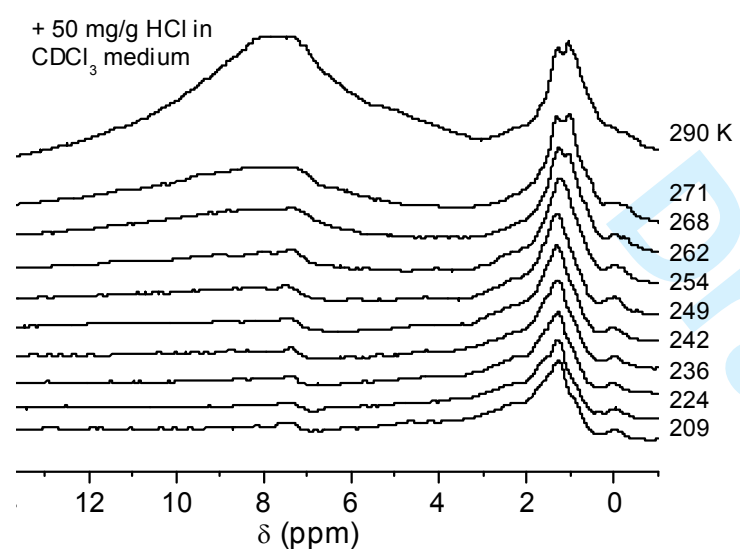

(c)

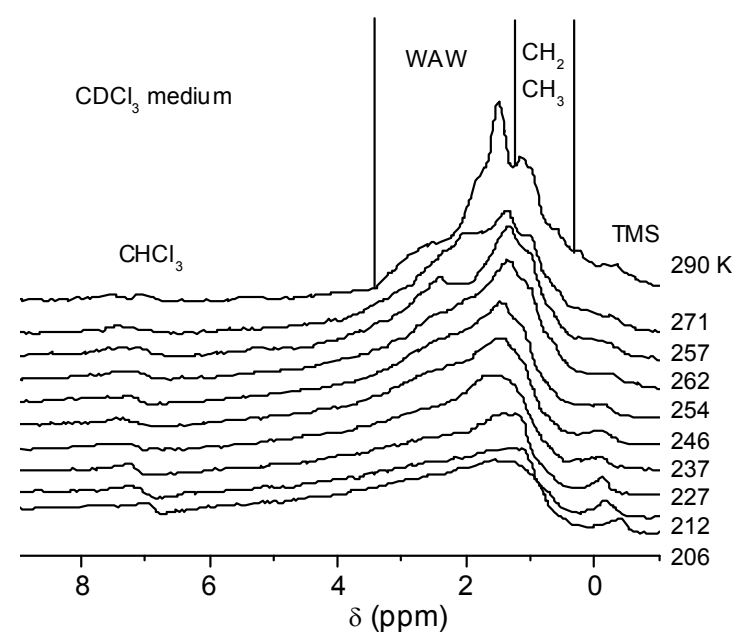

(b)

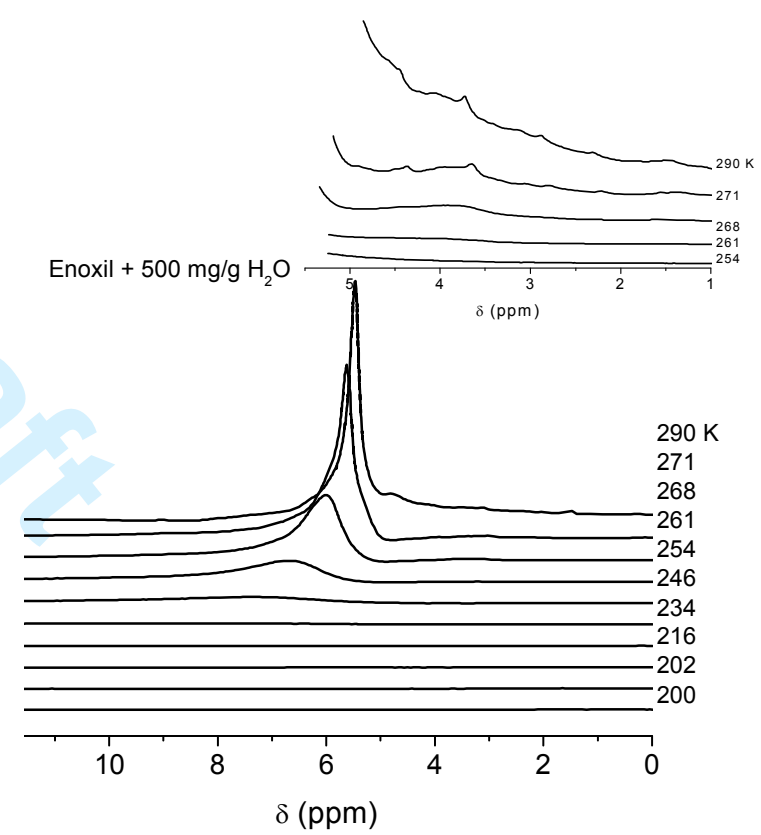

(d)

Fig.2. The ${ }^{1} \mathrm{H}$ NMR spectra taken at different temperatures of the initial Enoxil in air $(a)$ in the $\mathrm{CDCl}_{3}$ medium (b), supplemented with $50 \mathrm{mg} / \mathrm{g}$ of $36 \%$ solution $\mathrm{HCl}(\mathrm{c})$ and $500 \mathrm{mg} / \mathrm{g}$ water $(d)$. 
At immobilization of Enoxil on the nanosilica A-300 surface (1:1 ratio) in the spectra of the sample, after addition of $100 \mathrm{mg} / \mathrm{g}$ of distilled water,there is a wide signal of unfreezing water, which intensity decreases with lowering temperature, and the chemical shift depending on the temperature is in range $\delta_{\mathrm{H}}=6.5-8.5$ ppm (Fig. 3 and Fig. $4 a$ ). Such high values of the chemical shift cannot be explained exclusively by ordered network of water hydrogen bonds, because for the tetra-coordinated water in ice the value of chemical shift $\delta_{\mathrm{H}}=7 \mathrm{ppm}$ is characteristic [21]. Probably, Enoxil comprises a number of Bronsted acids, movable protons of which, by exchanging with protons of bound molecules of water, increase its chemical shift. Besides of the main signal, several low-intensity signals in the range $\delta_{\mathrm{H}}=1-5 \mathrm{ppm}$ are recorded in the spectra due to organic compounds dissolved in adsorbed water soluble or due to water with less ordered network of hydrogen bonds than for the main part of the bound water. It should be noted that in the spectra of water adsorbed on the initial silica (Fig. $4 b$ ) only one signal is recorded, the chemical shift of which varies slightly with temperature and corresponds to the values of $\delta_{\mathrm{H}}=4.5-5 \mathrm{ppm}$.

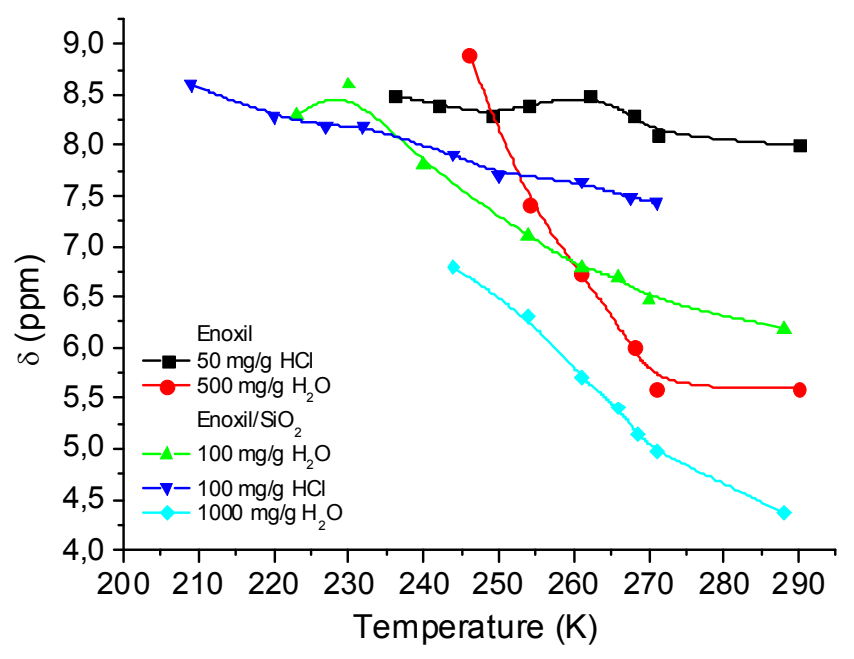

Fig.3. Temperature dependences of the chemical shift of unfrozen water for the initial Enoxil and that immobilized on the nanosilica A-300 surface. 
Replacement of water by $36 \%$ hydrochloric acid (Fig. $4 c$ ), results only in a slight shift of the chemical shift of the main signal of unfrozen water to the region of weak magnetic fields. One can therefore conclude that the immobilization of the Enoxil the surface of nanosilica largely keeps its antacid properties. Besides of the main signal in the spectra there are observed several signals with different chemical shifts in the region $\delta_{\mathrm{H}}=8-9 \mathrm{ppm}$, which can be associated with the clusters of more concentrated aqueous solutions of hydrochloric acid. As the main part of water is frozen (by decreasing the temperature), the concentration of acid in unfrozen phase is increasing, but it is still considerably lower than in liquid hydrochloric acid at the same temperature [20].

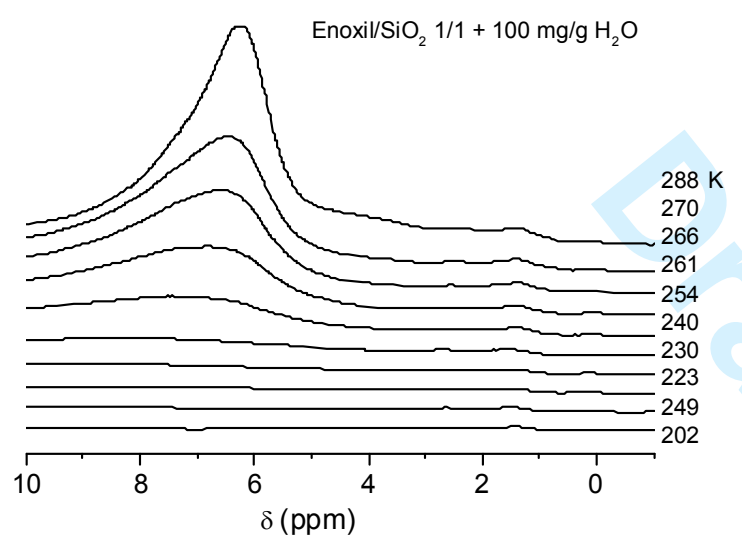

(a)

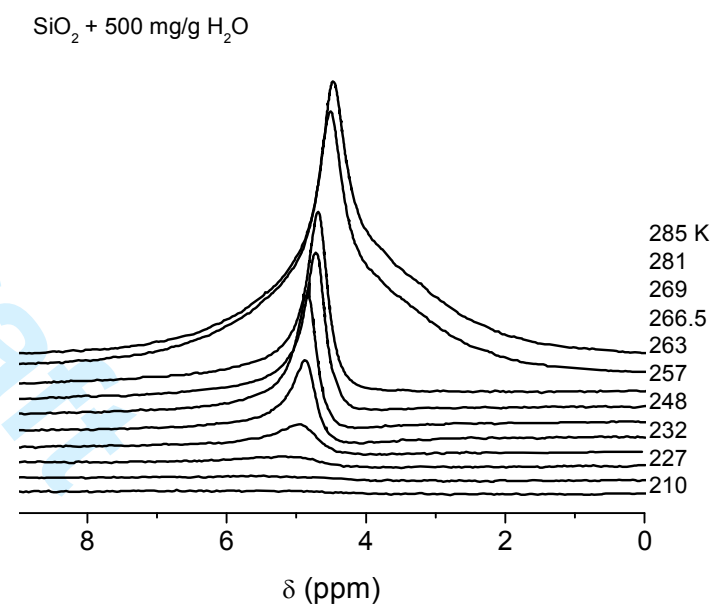

(b)

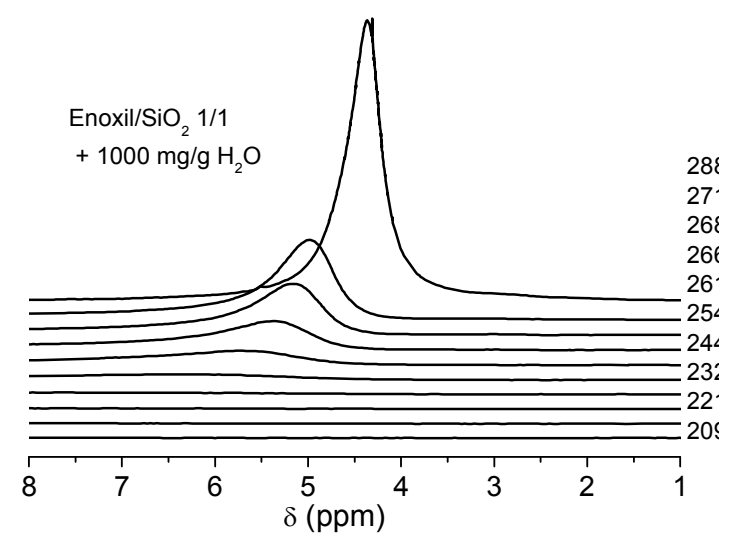

(d)

(c) 
Fig.4. Recorded at different temperatures ${ }^{1} \mathrm{H}$ NMR spectra of the composite system containing equal amounts of Enoxil and nanosilica A-300 supplemented with $100 \mathrm{mg} / \mathrm{g} \mathrm{H}_{2} \mathrm{O}$ (a); initial silica with $500 \mathrm{mg} / \mathrm{g} \mathrm{H}_{2} \mathrm{O}(b) 100 \mathrm{mg} / \mathrm{g} \mathrm{36 \%} \mathrm{HCl}(c)$ and $1000 \mathrm{mg} / \mathrm{g} \mathrm{H}_{2} \mathrm{O}(d)$.

For the composite sample containing $1000 \mathrm{mg} / \mathrm{g}$ of water (Fig. $4 d$ ) the chemical shift value of unfrozen water significantly decreases and becomes close to the chemical shift of liquid water [12].

The dependences of the concentration of non-frozen water (pure or part of the $\mathrm{HCl}$ solutions) on the temperature, for water adsorbed in the samples of Enoxil and its composite (1:1) with nanosilicaA-300 are shown in Fig. 5a. On the basis of these relationships according to the expressions (1) and (2), the curves of Gibbs free energy change in the layer of bound water and the distribution of the radii of water clusters in the process of melting the samples (Fig. $5 b$ and $5 c$, respectively) have been calculated. The ability to use equations (1)-(3) to calculate the thermodynamic characteristics and the distribution of the cluster radius of unfrozen water for solutions is due to the fact that at freezing of most aqueous solutions, the formation of crystals of frozen water and solute takes place. Water, as a rule, freezes in the form of hexagonal ice crystals [22]. The interaction of water with the molecules of the solute lowers the freezing point in accordance with the Raoult's law, and the difference of freezing points between the adsorbed water and adsorbed water solutions determines the contribution to the decrease of the free energy of the adsorbed water of solvation effects of the dissolved substance in water ( $\mathrm{HCl}$ in this case). Here, we have to notice that the distribution of the radii of clusters of adsorbed water differs considerably from the distribution of the radii of pores in the silica manufactured sample [13], in which there are peaks corresponding to the values $\mathrm{R}$ $=1$ and $20 \mathrm{~nm}$. The wide distribution $\Delta \mathrm{C}(\mathrm{R})$ indicates the possibility of the formation of 
clusters (domains) of water, the size of which is not related to the size of interparticle gaps in silica aggregates.

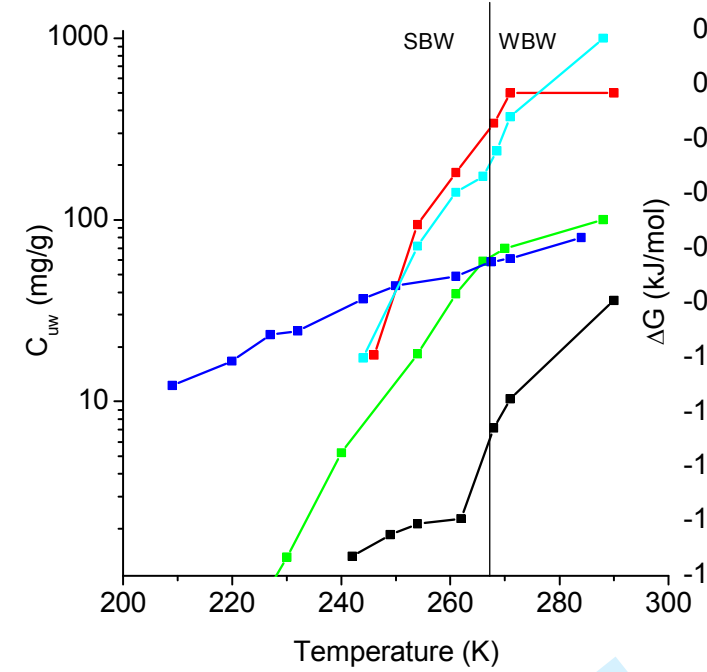

(a)

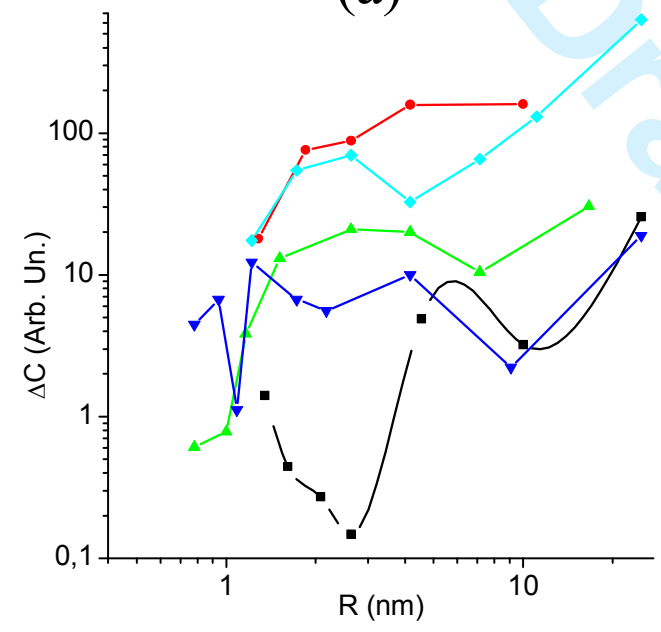

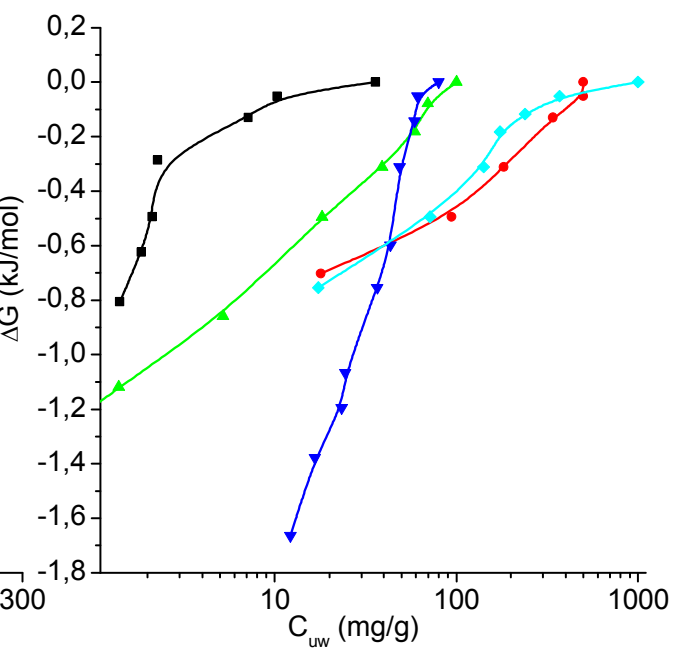

(b)

(c)

Fig.5. Temperature dependences of the concentration of unfrozen water $(a)$, the Gibbs free energy change of the concentration of non-freezing water $(b)$ and distribution of the radii of water clusters in the process of melting of the Enoxil and its composite with nanosilica A-300 (1:1) for adsorbed water and $\mathrm{HCl}$ solutions (c). 
Table 1 shows the thermodynamic parameters of the layers of non-freezing water in the studied systems. Wherein, the tightly coupled (SBW) part is considered that one of unfrozen water, which freezes at $T<265 \mathrm{~K}(\Delta \mathrm{G}<-0.5 \mathrm{~kJ} / \mathrm{mol})$ [12]. In the case of adsorption of Enoxil by $50 \mathrm{mg} / \mathrm{g}$ of hydrochloric acid, the bulk of water is in the weakly bound state, which is typical for low-concentration acid solutions. The $\Delta \mathrm{G}^{\mathrm{s}}$ value determines the maximum decrease in the free energy in the bound water layer [12]. This decrease can be determined as the interaction with both the phase boundaries (adsorption interactions) and solutes (solvation). The close $\Delta \mathrm{G}^{\mathrm{s}}$ values for adsorbed $\mathrm{HCl}$ solution and water can be due to the fact that the main mechanism of lowering the freezingpoint serves solvation (dissolution), and not the interaction with Enoxil solid particles.

A large number of both weakly and tightly-bound water $\left(\mathrm{C}_{\mathrm{uw}}{ }^{\mathrm{w}}\right.$ and $\mathrm{C}_{\mathrm{uw}}{ }^{\mathrm{s}}$, respectively), as well the $\gamma_{\mathrm{s}}$ value in the Enoxil, containing $500 \mathrm{mg} / \mathrm{g} \mathrm{H}_{2} \mathrm{O}$ shows its high tendency for hydration. If one assumes that in the specified quantity of water all the Enoxil powder passes on the dissolved state, then the $\gamma_{\mathrm{s}}$ value determines the gain of the free energy as a result of dissolution.

The difference between the characteristics of layers of unfrozen water, adsorbed on the surface of the composite Enoxil/ $/ \mathrm{SiO}_{2}$, with adsorption on it of $100 \mathrm{mg} / \mathrm{g}$ of water or hydrochloric acid is determined by solvation of $\mathrm{HCl}$ with water in the adsorption layer. Thus, in the case of water, the $\gamma_{\mathrm{s}}$ amount of $1.7 \mathrm{~J} / \mathrm{g}$ is determined predominantly by adsorption interactions (with silica particles and Enoxil) and the partial dissolution of Enoxil in adsorbed water. At adsorption of the Enoxil/ $/ \mathrm{SiO}_{2}$ composite by $\mathrm{HCl}$ solution, the $\gamma_{\mathrm{s}}$ value increases twice, that it also reflects the process of $\mathrm{HCl}$ hydration (or its ions) by adsorbed water as well as the interactions of $\mathrm{HCl}$ with organic components of Enoxil.

Distributions over the water cluster radius (domains) during the defrost of water suspensions (solutions) (Fig. 5c) show that in the studied systems poly-associates (clusters, 
domains) of water can be present, the radius of which is $20 \mathrm{~nm}$ or more. At adsorption by Enoxil powder of $50 \mathrm{mg} / \mathrm{g}$ of $\mathrm{HCl}$ the distributions have maxima corresponding to values $\mathrm{R}=$ 1.6 and $20 \mathrm{~nm}$. The close maximum values arerecorded in the case of $\mathrm{HCl}$ solution adsorption on the surface of Enoxil/ $\mathrm{SiO}_{2}$ composite. For other systems maxima are less pronounced, but there is a tendency to form clusters with a radius $R=2-4 \mathrm{~nm}$.

\section{Conclusions}

The Enoxil preparation contains about $6 \mathrm{wt} \%$ of residual water, which predominantlyis in the weakly associatedstate, recorded in ${ }^{1} \mathrm{H}$ NMR spectra as signals with a chemical shift $\delta_{\mathrm{H}}=<2 \mathrm{ppm}$, well observed in the environment of a weakly polar solvent $\mathrm{CDCl}_{3}$.

Since Enoxil is suitable for oral use, its hydration in the presence of $\mathrm{HCl}$, which is a part of the gastric juice, has been studied. It is established that the Enoxil preparation has antacid action, which manifests in the transformation of the $\mathrm{HCl}$ concentrated solution of in low-concentrated one on its surface. These properties are maintained as well in the composite system Enoxil/ $\mathrm{SiO}_{2}$.

At adsorption of hydrochloric acid by the composite Enoxil/ $\mathrm{SiO}_{2}$, on its surface a system of clusters of varying concentration of acid solution is formed.

Thermodynamic properties of water, bound by Enoxil and its composite with silica are largely determined by the process of dissolution of the Enoxil components in the interface water.

\section{Acknowledgment}

The research leading to these results has received funding from the People Programme (Marie Curie Actions) of the European Union's Seventh Framework Programme FP7/2007-2013/ under REA grant agreement PIRSES-GA-2013-612484. 


\section{References}

(1) Duca, Gh.; Lupascu, T.; Vlad, P.; Kulcitki, V.; Nastas, R. Chem. J. Mold. 2006, 1(1), 74.

(2) Kulcitchi, V.; Vlad, P.; Duca, Gh.; Lupascu, T. Chem. J. Mold. 2007, 2(1), 36.

(3) Lupascu, T.; Duca, Gh.; Lupascu, G. Enoxil - an ecological compound for the plant protection. ASM: Chisinau, 2010, 136 p. [In Romanian].

(4) Nemtoi, G.; Ciomaga, A.; Lupascu, T. Rev. Roum. Chim.2012, 57 (9-10), 837.

(5) Lupascu, T.; Duca, Gh.; Giurginca, M.; Vlad, P.; Lupascu, L.; Gromovoi, T.; Meghea, A. Key Eng. Mater. 2009, 415, 25.

(6) Lupascu, L.; Rudic, V.; Cotos, V.; Lupascu, T. J. Biomed. Sci. Eng. 2010 a,3 (8), 758.

(7) Lupascu, T.; Duca, Gh.;Gonciar, V. et al. Enoxil-ecological preparation for human health; ASM: Chisinau, 2012; 256 p. [In Romanian].

(8) Medical chemistry and clinical use of silica; Chuiko, A.A., Ed., Naukova Dumka: Kiev, 2003; 415 p. [In Russian].

(9) FAO/WHO Codex Alimentarius Commission List of Additives Evaluated for their Safety-in-Use in Food CAC/Fal 1-1973. USA Patents, No 573355, 1973.

(10) Krupska, T.V.; Barvinchenko, V.M.; Grygorieva, M.A.; Todosiychuk, T.S.; Turov, V.V. Farm. Zh. (Kiev, Ukr.), 2008, 1, 95.

(11) Krupska, T.V.; Turova, A.A.; Gun'ko, V.M.; Turov, V.V. Biopolym. Cell, 2009, 25 (4), 290. [In Russian].

(12) Gun'ko, V.M.; Turov, V.V.; Gorbik, P.P. The water at the interface; Naukova Dumka: Kiev, 2009; 694 p. [In Russian].

(13) Gun'ko, V.M.; Turov, V.V. Nuclear Magnetic Resonance Studies of Interfacial Phenomena; Taylor \& Francis: N. Y., 2013; 1076 p. 
Naukova Dumka: Kiev, 2011; 316 p. [In Russian].

(15) Gun'ko, V.M.; Turov, V.V.; Bogatyrev, V.M.; Zarko, V.I.; Leboda, R.; Goncharuk, E.V.; Novza, A.A.; Turov, A.V.; Chuiko, A.A. Adv. Colloid Interface Sci. 2005, $118,125$.

(16) Aksnes, D.W.; Kimtys, L. Solid State Nucl. Magn. Reson. 2004, 25, 146.doi:10.1016/j.ssnmr.2003.03.001

(17) Petrov, O.V.; Furo, I. Prog. Nucl. Magn. Reson. Spectrosc., 2009, 54, 97,doi:10.1016/j.pnmrs.2008.06.001

(18) Thermodynamic properties of individual substances; Glushko V.P., Ed., Nauka: Moscow, 1978; 495 p. [In Russian].

(19) Turov, V.V.; Gun'ko, V.M.; Turova, A.A.; Morozova, L.P.; Voronin, E.F. Colloids Surf., A, 2011, 390, 48.

(20) Günther, H. NMR Spectroscopy Basic Principles, Concepts, and Applications in Chemistry; Wiley-VCH: Weinheim, 2013; 734 p.

(21) Kinney, D.R.; Chaung, I-S.; Maciel, G.E. J. Am. Chem. Soc. 1993, 115, 6786.doi: $10.1021 / \mathrm{ja} 00068 \mathrm{a} 041$

(22) Water and aqueous solutions at temperatures below $0^{\circ} \mathrm{C}$; Frank, F., Ed., Naukova Dumka: Kiev, 1985; 388 p. [In Russian]. 
Table 1.Characteristics of water layers adsorbed by the Enoxil preparation and its composite systems Enoxil/ $/ \mathrm{SiO}_{2}$.

\begin{tabular}{cccccc}
\hline \multirow{2}{*}{ System } & Adsorbate & $-\Delta \mathrm{G}^{\mathrm{s}}$, & $\mathrm{C}_{\mathrm{uw}}^{\mathrm{s}}$, & $\mathrm{C}_{\mathrm{uw}}{ }^{\mathrm{w}}$, & $\gamma^{\mathrm{s}}$, \\
& & $\mathrm{kJ} / \mathrm{mol}$ & $\mathrm{mg} / \mathrm{g}$ & $\mathrm{mg} / \mathrm{g}$ & $\mathrm{J} / \mathrm{g}$ \\
\hline \multirow{2}{*}{ Enoxil } & $50 \mathrm{mg} / \mathrm{g} \mathrm{HCl}$ & 1 & 2.5 & 35 & 0.21 \\
& $500 \mathrm{mg} / \mathrm{g} \mathrm{H}_{2} \mathrm{O}$ & 1 & 175 & 325 & 8.6 \\
\hline Enoxil/ $\mathrm{SiO}_{2}$ & $100 \mathrm{mg} / \mathrm{g} \mathrm{H}_{2} \mathrm{O}$ & 1.7 & 20 & 80 & 1.7 \\
& $100 \mathrm{mg} / \mathrm{g} \mathrm{HCl}$ & 2.4 & 50 & 30 & 3.5 \\
& $1000 \mathrm{mg} / \mathrm{g} \mathrm{H}_{2} \mathrm{O}$ & 1.2 & 170 & 430 & 6.8 \\
\hline
\end{tabular}




\section{Figure captures:}

Fig. 1.Microphotograph images of the initial Enoxil in its native state: $a$ - in the reflected light at x100 magnification; $b, c-$ in the transmission mode at x100 and x1000 magnification respectively; and also of the preparation fixed on the silica surface: $d$ - in reflection mode with increasing by $\mathrm{x} 100 ; e$ - in transmission mode with increasing by $\mathrm{x} 1000 ; f$ - in transmission mode at $\times 1000$ magnification in the presence of water.

Fig.2. The ${ }^{1} \mathrm{H}$ NMR spectra taken at different temperatures of the initial Enoxil in air $(a)$ in the $\mathrm{CDCl}_{3}$ medium (b), supplemented with $50 \mathrm{mg} / \mathrm{g}$ of $36 \%$ solution $\mathrm{HCl}(\mathrm{c})$ and $500 \mathrm{mg} / \mathrm{g}$ water $(d)$.

Fig.3. Temperature dependences of the chemical shift of unfrozen water for the initial Enoxil and that immobilized on the nanosilica A-300 surface.

Fig.4. Recorded at different temperatures ${ }^{1} \mathrm{H}$ NMR spectra of the composite system containing equal amounts of Enoxil and nanosilica A-300 supplemented with $100 \mathrm{mg} / \mathrm{g} \mathrm{H}_{2} \mathrm{O}$ (a); initial silica with $500 \mathrm{mg} / \mathrm{g} \mathrm{H}_{2} \mathrm{O}(b) 100 \mathrm{mg} / \mathrm{g} \mathrm{36 \%} \mathrm{HCl}(c)$ and $1000 \mathrm{mg} / \mathrm{g} \mathrm{H}_{2} \mathrm{O}(d)$.

Fig.5. Temperature dependences of the concentration of unfrozen water $(a)$, the Gibbs free energy change of the concentration of non-freezing water $(b)$ and distribution of the radii of water clusters in the process of melting of the Enoxil preparation and its composite with nanosilica A-300 (1:1) for adsorbed water and $\mathrm{HCl}$ solutions $(c)$. 